\title{
What is the Environmental Performance of Firms Overseas?: An Empirical Investigation of the Global Gold Mining Industry
}

\author{
Gary Koop \\ Department of Economics \\ University of Strathclyde \\ Glasgow, UK \\ G4 OGE \\ Lise Tole* \\ Department of Economics \\ University of Strathclyde \\ Glasgow, UK \\ G4 OGE \\ Phone: +44 (0) 141 548-4556 \\ Fax: +44 (0) 141 548-445 \\ email: lise.tole@strath.ac.uk
}

Keywords: Bayesian stochastic frontier analysis; efficiency; environmental regulations and plant performance; pollution havens; regulatory chill; gold mining.

JEL Classification: Q3, Q56, C11, C23.

*Address to which all correspondence should be sent. The authors would like to thank Andreas Tegen \& Magnus Magnusson (RMI) for their assistance. The project was conceived while the second author was visiting the World Bank. She would like to thank them for their hospitality. Both authors would like to thank participants at the UK Conference on Productivity and Efficiency (UK-EPAN) for useful comments. This work was supported by a grant from the British Academy. 
Abstract: Using a large plant level data set, this paper carries out an econometric analysis of the environmental performance of multinational firms in the gold mining industry worldwide. The aim of the analysis is to determine if, by looking at the actual environmental performance of firms (as opposed to inferring such behavior from location decisions), we can shed any light on important questions in the literature on firm location decisions: Do pollution havens exist in the gold mining industry? Do foreign controlled gold mines perform environmentally worse or better than their domestic counterparts? We develop different ways of measuring environmental performance within the context of a Bayesian stochastic production frontier approach. In particular, we derive different ways of measuring technical and environmental efficiency. When we implement these methods in our empirical work, we find that results are robust across different models and ways of measuring efficiency. We find that gold mines exhibit a wide range of environmental efficiencies; some are clearly more efficient than others, in other words. However, and most importantly for our questions, we find that this variation in efficiencies cannot be systematically related to mine characteristics such as whether they are foreign or domestically controlled or whether they are located in developed or developing countries.

Keywords: Bayesian stochastic frontier analysis; efficiency; environmental regulations and plant performance; pollution havens; regulatory chill; gold mining.

JEL Classification: Q3, Q56, C11, C23. 
This paper attempts to shed light on important economic and environmental policy questions as: Do firms operating in developing countries behave differently from those operating in developed countries? Do foreign controlled firms exhibit different environmental performance from domestically controlled ones?

The answers to these questions have immense economic, welfare and environmental implications for rich and poor countries alike. In this paper, we address these questions using a new data set of gold mines worldwide. From a firm decision and environmental perspective, the gold mining industry provides an important case study for analysis of these questions: a) It is truly global in the extent of its reach. b) It produces substantial environmental pollution and degradation in comparison to other types of economic activity. Recently, there has been much public concern over and media interest in the environmental costs of gold production, especially in the developing world. For example, the New York Times has recently run a series of articles on the environmental and social impacts of multinational gold mining firms (see New York Times 2006a,b; 2005a,b,c). It alleges that many firms - a large number of them Fortune 500 firms - are breaching national environmental regulations, causing serious pollution and environmental degradation in the process. These claims have been vigorously denied by the companies themselves. In response to the accusations, the world's largest gold producer, the US multinational firm, Newmont, declared angrily that it "regards American environmental standards as its measures overseas" (New York Times 2004). In addition, a large academic literature (discussed in the next section) exists which is concerned with the general issue of the environmental performance of firms in poor countries and, in particular, with whether environmental regulation influences firm location decisions.

From an econometric point of view, gold mining is also an ideal industry in which to investigate these issues. There are hundreds of gold mines located throughout the world, in countries as diverse in income and environmental standards as the USA and Gabon. In any country, mines can also either be foreign or domestic controlled and owned. All produce the same type of waste and roughly follow the same sequence of steps to do so. Thus, there are enough established gold mines in operation today across a wide range of countries to provide meaningful statistical comparisons. Despite the potential of the gold industry to shed light on the nature of firm location decisions, to our knowledge, there have been no papers that address issues of environmental performance within the mining industry on a global level. No doubt this is due to the shortage of adequate data on the activities of multinationals at a sufficient level of disaggregation to carry out a meaningful analysis. The plant level data set we construct in this paper, one that involves the activities of 419 mines over a ten year period, enables us to surmount many of these data problems to a great extent.

In this paper, we argue that our questions of interest can be related to efficiency issues. A formal definition of environmental efficiency will be provided below, but intuitively, environmental inefficiency will be associated with a mine being environmentally lax and polluting excessively (relative to other comparable mines). This focus on efficiency motivates our econometric specifications based on stochastic frontier models. However, we have to move beyond the standard stochastic frontier approach to efficiency analysis with a single output. That is, in our case, mines are producing an undesirable 
output, waste pollution. Furthermore, gold mining may also involve the production of other metals, such as silver and copper. Hence our model must allow for the production of multiple outputs. The stochastic frontier literature has not settled on a standard single approach for dealing with production when there are multiple outputs and some are undesirable. For this reason we define a variety of specifications for the production frontier.

Related to the issue of undesirable outputs is the question of how to define "environmental efficiency". This issue leads us to a consideration of various ways of defining environmental inefficiency relative to a frontier. We subsequently implement these different specifications and efficiency definitions in our empirical work. We find that our basic results are robust across all specifications of the frontier and ways of measuring environmental efficiency. We find that the gold mines do vary widely in terms of their environmental efficiency; some are clearly much more efficient than others. However, and most importantly for addressing our environmental questions of interest, we find that this variation in efficiencies cannot be systematically related to mine characteristics such as whether a mine is foreign or domestically owned or whether it is located in a rich or a poor country.

The remainder of this paper is as follows: Section 2 provides further motivation for the nature of our study in the context of a review of key papers in the relevant literature. Section 3 provides a discussion of efficiency measurement with multiple (possibly undesirable) outputs. Section 4 provides a comprehensive description of our data set and discusses data issues. Section 5 presents our empirical results and Section 6 concludes.

\section{Motivation and Literature Review}

Recently, there has been much academic debate over the role of environmental regulations as determinants of firm location decisions. Economic theorists have predicted that as poor countries increasingly integrate into the global economy, their comparatively weak environmental regulations will lead them to become destinations of choice for polluting industries, or "pollution havens". Anxious to cut costs in a globally competitive world, foreign firms, they argue, will be attracted to poor countries, where environmental standards are weaker and compliance costs are considerably lower than at home. However, over time, developed countries in turn will be forced to progressively weaken their environmental standards in an attempt to reverse the flow of outward investment to poor countries. The end result will be a "race-to-the bottom", with the most polluting country setting the global standard of environmental quality to which all countries eventually gravitate. A closely related body of literature, the

"regulatory chill" literature suggests that while environmental stringency does not lead foreign firms to migrate to countries with lax environmental standards, competitive pressures can nevertheless affect environmental decision-making in host countries, preventing the latter from enacting stricter environmental standards for fear of losing their competitive edge (Esty and Geradin 2001; Nordström and Vaughan 1999). This literature argues that, while lax environmental regulations may not be driving foreigners to set up operations abroad, they may indirectly be influencing the climate of policymaking in poor countries in a way that leads to no appreciable rise in standards (Zarsky 1997; Neumayer 
2001).

In contrast to the theoretical literature (see, e.g. Baumol and Oates 1988), empirical studies have found mixed and largely weak support for the existence of pollution havens. For example, Bartik (1998) finds that environmental stringency (measured using variables such as state spending on air and water quality control, allowed particulate emissions on industrial boilers, and average costs of compliance) had only small and insignificant impacts on locational decisions of US Fortune 500 branch plants. Levinson (1996) finds similarly weak support in his study of the influence of state environmental regulations on firm location decisions in the US. Only one indicator - an index measure of the strength of state environmental regulations - was consistently significant but the magnitude of its coefficient was small and economically had little significance. McConnell and Schwab (1990) and Friedman et al. (1992) also find little support for the claim that environmental stringency may have determined the location decisions of foreign investment in new manufacturing branch plants between 1977 and 1988. Using pollution abatement expenditures per state gross product originating in manufacturing industries, Friedman et al. 1992 find that only if Japanese branch plants are included is environmental stringency significant and negative, indicating that Japanese MNCs (multinational corporations) did not tend to set up in states where pollution control costs were high. However, this finding did not hold when only European MNCs were considered. Once again, the impact of environmental stringency was quite small.

Similar findings derive from macro level studies examining the relationship between imports, exports and the consumption of dirty vs. clean industries. In their classical study, Grossman and Krueger (1993) find no evidence to suggest that higher pollution abatement costs in the US had a significant impact on imports from Mexico or from maquiladora sectors in particular. Birdsall and Wheeler (1993) find similar results in their study of Latin America, arguing that closed economies are more likely to favor pollution intensive industries, while openness actually encourages cleaner industry through the importation of developed-country pollution standards. In contrast, Low and Yeats (1992) do find some evidence of an association between the rise in environmental control costs in developed countries and the creation of pollution havens in poor countries.

More recent evidence (both macro and micro) reveals much the same mixed but generally weak support for the pollution haven hypothesis, although findings of later studies tend to be more significant than earlier ones. Becker and Henderson (2000), for example, find that air quality regulations significantly reduce the number of new firm births in US counties in non-attainment of federal air pollution standards, especially in the later years of the attainment period. Findings hold for different types of firms, not just large ones, with corporate firms being more influenced by non-attainment status than large firms. In their study of pollution abatement costs and foreign direct investment flows into US states, Keller and Levinson (2002) find some evidence to suggest that abatement costs may have a small deterrent effect on foreign investment, particularly in pollution-intensive industries (e.g. chemicals). The measured effect, however, is very small: A doubling of their cost index is associated with FDI decreases of less than 10\%. Unlike other studies, they adjust for industrial composition for each state to account for the uneven nature of industrial composition among states (i.e. some states 
have cleaner industrial compositions than others and thus may by their very nature attract less FDI). However, several recent studies for the US that endogenize local environmental regulations find that pollution-intensive plants respond adversely to stringent environmental regulations (List and Co 2000; List et al. 2003; Greenstone 2002). For example, List and Co (2000) find a strong determinative role for environmental regulations among foreign firm location decisions in the US states for 1986-1993. This result holds for all their measures of environmental stringency, even after controlling for pollution intensive vs. non-intensive pollution industries.

In contrast to these US studies, Eskeland and Harrison (2003) find that abatement costs are not a significant determinant of the distribution of foreign investment in Mexico, Venezuela, or Cote d'Ivoire. They find that foreign FDI flows are associated with less energy use, the study's measure of pollution intensity. Dean, Lovely, and Wang (2004) in a study of foreign equity joint ventures in China between 1993-1996, find that Chinese-sourced investments are deterred by areas with more stringent pollution regulations. In contrast, equity joint ventures from both Chinese and non-Chinese sources were attracted to areas with more stringent regulations, particularly the latter. This result held irrespective of pollution intensity of industry. Their work stresses the importance of accounting for firm heterogeneity in studies of FDI and environmental stringency. In contrast, Smarzynksa and Wei (2001), in their study of the investment choices of multinational firms in the former Soviet Union and Eastern Europe, find little evidence that weak environmental regulations attract foreign investment or that lower standards are a prominent pull factor in pollution-intensive FDI flows. Unlike other studies, they control for the problem of corruption in environmental laxity.

The above brief review brings to light a number of empirical shortfalls that may explain the mixed and generally weak statistical findings of the literature. These shortfalls can be summarized thus:

a) The vast majority of studies focus on manufacturing rather than extractive resource industries. For the most part, natural resource extraction and associated production processes are large-scale operations, with high energy and environmental costs per output. These costs are typically far greater than in manufacturing industries. One good example is the mining of minerals and metals. Not only is mining a highly pollution intensive activity even when the most modern and sophisticated extraction methods are used, its impacts on the environment are both immense and pervasive. Given that per unit abatement and clean-up costs will typically be much higher than for manufacturing industries, environmental stringency may potentially be a more significant factor in firm location decisions in an extractive industry such as mining. Moreover, for many poor countries, extractive industries like mining are the main source of foreign exchange revenues. Many poor countries rich in metals and minerals resources compete aggressively for foreign capital by providing favourable tax and other investment incentives for investors. Substantial investment is necessary for the development of even one mine, as mining is a highly capital intensive enterprise. Despite its economic importance for developing countries and its potentially huge environmental impacts, the mining industry has not been systematically studied in the firm location literature.

b) If environmental stringency really does not figure prominently in the location decisions of firms as some of the literature suggests, it may be because multinational manufacturing companies oper- 
ating overseas have already adopted the newer, cleaner, and superior environmental technologies of their rich world, home markets. The obverse of the pollution haven hypothesis, the "pollution halo" hypothesis, argues that foreign firms are induced to respond in this fashion due to their sensitivity to the "green" demands of shareholders and consumers (Zarsky 1999). However, while this may be the case for the manufacturing industries, the nature of extractive industries makes it less likely that shareholders or consumers will have information on these environmental impacts. To begin with, the extraction of minerals from the earth is the first of many stages in the life cycle of a manufactured consumer product. The environmental impacts of extractive industries may not figure as prominently in consumer and/or shareholders' minds as the tangible products created from the raw materials. Second, because extractive industries, particularly mining, are often carried out in remote, depopulated regions, environmental information is often difficult to obtain because monitoring of plant behaviour is sporadic or non-existent. Thus, extractive industries may not be under the same kind of pressure as manufacturing industries to adopt to higher environmental standards.

c) Misspecification arising from the use of aggregate and limited data sets. Due to data restrictions, empirical studies must overwhelmingly rely on aggregate data, at best firm or industry level data (i.e. not plant level data). Moreover, due to lack of available data, a large number of studies must focus on just one or a few countries. Most of this research has been carried out on US or foreign firms operating within the contiguous 48 states of the US (e.g. Becker and Henderson 2000; List and Co 2000; List 2001; McConnell and Schwab 1990). These drawbacks mean that existing studies are poor at picking up important sources of heterogeneity in multinational firms' decision-making and performance at the global level. Studies also tend to suffer from the use of poorly defined measures of pollution intensity (e.g. national standards for lead in petrol), which may have little if any relevance for the production processes of a particular firm. Similar misspecification problems arise when pollution intensity has to be inferred from aggregate sector or industrial emissions data. A good example of the latter is the World Bank's sector estimates of pollution intensity, drawn from its Industrial Pollution Projection System (IPPS). Measured as pollution per unit output and pollution per employee, these estimates have been widely used to measure pollution loads in industrial sectors. Since they are based on a large sample of production and data emissions of firms in the US in 1987, their application to developing countries may be limited. They also make the questionable assumption that pollution intensities remain fixed. Hence any changes induced by trade liberalization (e.g. composition, scale or technique effects) will not be picked up in the study.

This study attempts to address these shortfalls. It uses a truly global data set, one that observes characteristics of firms operating in a wide range of countries at different levels of development and exhibiting differing levels of environmental stringency. Our data set also allows us to compare foreign with domestic controlled firms operating in the same country in the range of rich and poor countries in which they are observed to operate. With this information we are able to investigate more fully the complex relationships between country choice and environmental outcomes than current studies do that use either firm level measures of inter or intra-country location choices or FDI flows or focus on only one or a few poor countries. 
Moreover, in contrast to many studies that focus on environmental intentions expressed as a location decision or investment flow, this study focuses on the actual environmental performance of mines once firms have set up operations, both at home and abroad. This approach allows us to measure directly what firms are "up to" from an environmental point of view rather than inferring their environmental behavior through their location or investment choices. Moreover, by linking pollution directly to each mine that creates it, we also avoid using aggregate or national measures of pollution

output (e.g. $\mathrm{SO}^{2}$ emissions) or de jure statutory indices of environmental performance (e.g. lead content limits in gasoline) that may have little meaning for the firm. While some developing countries have exemplary environmental regulations on their statute books, in practice, compliance is often very weak because monitoring is lax or non-existent. While they do provide a good overall proxy for a country's regulatory stringency, aggregate pollution emissions for an industry do not effectively link the individual firm's location decision with its environmental intentions since these kind of measures represent a country's total emissions.

Our context for analysis of these relationships is the industrial gold mining industry. We use a panel data series of gold mine producers for 1996-2005. The data set provides an array of information on the characteristics of every major player in this industry around the world. As discussed in the introduction, we associate the performance of each mine to its environmental efficiency. However, there are some important modelling issues associated with the definition of environmental efficiency to which we now turn.

\section{Efficiency Measurement with Multiple, Possibly Undesirable, Out- puts}

In this section, we briefly describe some of the issues relating to efficiency measurement with multiple, possibly undesirable outputs. Our goal is to provide reasonable definitions of technical and environmental efficiency. We break the discussion into two parts; the first discusses multiple output production where all outputs are desirable (i.e. "goods") while the second discusses the complications caused by the addition of undesirable outputs (i.e. "bads"). Both of these issues are very important since mines often produce many outputs (e.g. gold, silver and copper often are all produced from similar ore). Furthermore, as discussed in the introduction, the pollution that mines produce is immense, and is becoming an important policy issue.

Before we begin, we stress that we are considering only the case where we use data on inputs and outputs (and geological characteristics) of mines to estimate best-practice technology. Efficiency is then measured relative to this best-practice technology. That is, if mine A and B have the same inputs and geological characteristics and are producing the same amount of bads, but mine $\mathrm{A}$ is producing more good output than mine B, then we say mine A is technically more efficient than mine B. Similarly, if mine A and B have the same inputs and geological characteristics and are producing the same amount of good outputs, but mine $\mathrm{A}$ is producing less pollution than mine $\mathrm{B}$, then we say mine $\mathrm{A}$ is environmentally more efficient than mine $\mathrm{B}$. We do not formally model the decision process 
of the mine nor do we address the question of whether mines are acting optimally (except in the sense that inefficiency is not optimal). Typically, investigation of the latter questions involves data on input prices and costs which are not available in our data set. Examples of empirical mining papers which do investigate such economic issues include, among many others: Cairns (1981); Farrow (1985); Lasserre (1985); and Young (1992).

In this paper, we adapt an econometric approach developed in Fernández, Koop and Steel (2000, 2005) to our application. However, it is worth mentioning some alternative approaches to productivity and efficiency measurement with multiple, possibly bad, outputs when only data on inputs and outputs is available. Many papers adopt a non-econometric approach involving index number methods or data envelopment analysis. In terms of multiple output production, Caves, Christensen and Diewert (1982) is an influential early paper. Pittman (1983) extended their approach to the case of undesirable outputs. Pittman's framework has been adopted or adapted in many later papers, such as Fare, Grosskopf, Noh and Weber (2005). Tyteca (1996) provides a review of some of this literature with a focus on the environmental efficiency aspect. For many cases, such non-statistical approaches are undoubtedly reasonable. However, in noisy data sets it might be preferable to formally model measurement error and adopt an econometric approach (Koop, Osiewalski and Steel 1997 provides a more detailed discussion of these issues).

There are few econometric papers relating to efficiency analysis in multiple-output production functions. As discussed in detail in Fernández, Koop and Steel (2000), a statistical model of multipleoutput production is inherently multivariate: the dependent variables are the outputs. In essence, this means we need a multiple equation model. Since most of the previous econometric approaches in the literature (e.g. Adams, Berger and Sickles 1999; Löthgren 1997; and Reinhard, Lovell and Thijssen 1999) involve single equation models, we do not adopt any of these approaches in the present paper. Atkinson and Dorfman (2005) is a recent paper that uses Bayesian generalized methods of moments in a model of multiple output production involving a single bad output.

\section{Multiple Output Production}

The best-practice technology for producing a vector of $p$ outputs, $y=\left(y_{1}, . ., y_{p}\right)^{\prime}$, from a vector of $m$ inputs, $x=\left(x_{1}, . ., x_{m}\right)^{\prime}$, can be described using a transformation function:

$$
f(y, x)=0
$$

We assume this production frontier is separable. (The assumption of separability can be relaxed as described in Fernández, Koop and Steel 2005). Thus, the transformation function has the form:

$$
g(y)=h(x)
$$

The left and right hand sides of this equation can be interpreted as aggregate output (or, equivalently, as defining a production possibility curve) and production frontier, respectively. (1) defines the maximum feasible output that can be achieved for given inputs. In practice, mines might not achieve this 
maximum and the deviation from this maximum is used in our efficiency measures. In the following material we will let $y$ and $x$ be the actual output and input choices of a mine (as opposed to the theoretical maximum or minimum values for these variables).

There are a variety of different ways that technical efficiency can be measured in this setup. The reader is referred to Fernández, Koop and Steel (2005) for a more complete discussion of alternative efficiency measures. Here, we begin with the most common measure of efficiency: radial outputoriented technical efficiency, $\tau_{R O}$. The inverse of this $\left(\right.$ i.e. $\left.1 / \tau_{R O}\right)$ measures the amount by which all $p$ outputs must be proportionally increased in order to get to the frontier. For an inefficient mine we obtain $\tau_{R O}<1$, whereas $\tau_{R O}=1$ corresponds to full efficiency. Since $g($.$) determines the maximum$ feasible output by a mine with inputs $x$, radial-oriented technical efficiency is defined by:

$$
g\left(\frac{y_{1}}{\tau_{R O}}, \ldots, \frac{y_{p}}{\tau_{R O}}\right)=h(x)
$$

where $0<\tau_{R O} \leq 1$. Note that, in this setup, $\tau_{R O}$ is equal to the output-distance function used by some researchers (see, e.g., Shephard 1970 or Färe and Primont 1995).

An alternative efficiency measure is radial input-oriented efficiency, $\tau_{R I}$. It measures the amount by which all inputs must be proportionately decreased to get to the frontier. That is, efficient production is defined as:

$$
g\left(y_{1}, \ldots, y_{p}\right)=h\left(\tau_{R I} x_{1}, \ldots, \tau_{R I} x_{m}\right)
$$

which implicitly defines $\tau_{R I}$.

Radial-oriented efficiency measures such as those given in (2) and (3) are the most popular ones. However, as we shall discuss below, for our mining application they might not be the most appropriate. It is also possible to define efficiency measures relating to a particular input (or output). That is, instead of asking "by how much can all inputs be decreased proportionally without reducing existing production levels?" one can ask "by how much can the $j^{\text {th }}$ input be decreased (leaving all other inputs unchanged) without reducing existing production levels?". Analogous to (3), individual input-oriented efficiencies, $\tau_{I j}$ for $j=1, . ., m$, can be defined implicitly by noting that efficient production corresponds to:

$$
g\left(y_{1}, \ldots, y_{p}\right)=h\left(x_{1}, \ldots, \tau_{I j} x_{j}, \ldots, x_{m}\right) .
$$

Individual output-oriented efficiencies, $\tau_{O j}$, can be defined through:

$$
g\left(y_{1}, \ldots, \frac{y_{j}}{\tau_{O j}}, \ldots, y_{p}\right)=h\left(x_{1}, \ldots, x_{m}\right) .
$$

In our empirical work, we use only gold mines (i.e. mines whose main output is gold). Many of these mines only produce gold. However, some produce other metals. Thus, it is possibly important to consider several outputs (i.e. gold, silver and copper) in the production possibility curve. Since these are predominantly gold mines, a measure of gold-oriented technical efficiency would be of interest, but radially-oriented efficiency measures may not be sensible. Consider, for instance, what the shape of the production possibility curve would be if gold and copper are the two outputs, but only a few firms 
produce copper. For the mines that produce no copper, their radially-oriented efficiency measures will (sensibly) be equivalent to their gold-oriented efficiency measures. However, the shape of the production possibility curve relating to copper production will be heavily influenced by the few firms which do produce copper. They could easily appear very near the frontier in the copper direction (and thus their radially-oriented efficiency measure could be near one) even if they are inefficient in gold production. This kind of story is meant to motivate why traditional radially-oriented efficiency measures may not be of primary interest. Accordingly, in our empirical work we focus on gold-oriented measures.

\section{Undesirable Outputs}

The literature has explored several different ways that the previous framework has been extended to accommodate undesirable outputs. In our empirical work, we investigate different possibilities. The simplest thing to do is to treat the bad output as an input. The justification for doing this arises from the observation that, in many technologies, the relationship between pollution and output is very similar to that of a regular input and output. For instance, more output can only be produced with more labor (a conventional input) and more pollution. A few papers which adopt this approach (and offer further justifications for it), include: Cropper and Oates (1992); Koop (1998); Pittman (1981); and Reinhard, Lovell and Thijssen (1999). In Atkinson and Dorfman (2005), the bad output is labelled a "technology shifter", but enters in the same manner as an input in (1). If a bad output is treated as an input, then a natural definition of "environmental efficiency" follows immediately. That is, we can simply use the individual input-oriented efficiency (i.e. $\tau_{I j}$ ) defined by (4) corresponding to the bad as environmental efficiency.

A second way to treat the bad output is to transform it so that it can be interpreted as a good output (see Atkinson and Dorfman 2005, for a discussion of this issue and Fernández, Koop and Steel 2005 for an application). That is, higher values of "good" outputs are desirable, but higher values of "bad" outputs are undesirable. But if we include an inverse transformation of the bads, then they can be interpreted as goods. For instance, if $b$ is a bad output, we could include it in (1) by defining a new "good" output (and label it the $j^{t h}$ output), $y_{j}=\frac{1}{b}$. If the bads, suitably transformed, are included in this manner then a natural definition of "environmental efficiency" can be found based on the individual output-oriented efficiency, $\tau_{O j}$, defined by (5) associated with the transformed bad output. ${ }^{1}$ The exact transformation required to produce "environmental efficiency" from this outputoriented efficiency is given on pages 423-424 of Fernandez, Koop and Steel (2005).

Note that we have so far defined different measures of technical and environmental efficiency through equations such as (2) through (5), which specify fully efficient production. However, each definition implies a single efficiency measure. Intuitively, the actual output of each mine will lie inside the production frontier. We can measure this "deviation from frontier" using our econometric methods. However, to associate this deviation from the frontier with an efficiency measure, we have to make a choice. For instance, if we choose to specify fully efficient production using (2), then the "deviation from frontier" is interpreted as technical efficiency. If we choose (5), then the "deviation from frontier" 
is interpreted as an individual output-oriented efficiency. As discussed in detail in Fernández, Koop and Steel. (2005), this is sensible. For each observation, we can measure a "deviation from frontier" in many different directions (e.g. in a radial sense, in a horizontal sense, a vertical sense, etc.) and, thus, have many possible efficiency definitions. But, in a given econometric model, we can only choose one of them. Put informally, we can either measure environmental efficiency or technical efficiency, but not both at the same time. Full details of our econometric methods, including the transformations which turn the deviation from the frontier into a particular efficiency definition, are given in Appendix A.

We now have a range of different measures of technical and environmental efficiency. In our empirical work, we calculate all of these measures, reasoning that a better understanding of our data set will be found by looking at it from several different (sensible) angles, rather than a single one.

\section{Data}

The mine-level data set for this analysis covers the years 1996 through 2005 and was derived from a variety of sources, such as company reports, websites and other independent industry mining sources. It has been supplemented with information and statistics from international, regional and national mining publications. More details of the data set, much of which has been collected by an independent mining consultancy firm, can be found in Appendix B. Table 1 in this section provides a summary of data definitions, acronyms and measures. The database used in this study has detailed information on a range of characteristics relating to gold mining production: metal, grade, ore production, ore resources and reserves, mining methods, capital and labor inputs, controllership status (i.e. foreign or domestic) and country location and income. We have observations for 2211 mine-years (i.e. 419 mines observed for up to 10 years). Note that missing data for some variables and the fact that some mines did not open until after 1995 mean that not all mines have complete data for the entire 10 year period. Hence our data set is an unbalanced panel.

\section{Dependent Variables}

Our main dependent variable is a measure of output: gold production (designated by the chemical symbol AU) measured in tonnes. However, many of the mines in the sample produce other outputs alongside gold. In this paper, we also measure outputs in mines that produce two other key metals in addition to $\mathrm{AU}$ : copper (CU) and silver (AG), measured in kilotonnes and tonnes, respectively. In addition, we also include a dependent variable measuring the yearly value of all metals, AU, AG and $\mathrm{CU}$, expressed in millions of US dollars. In some of our specifications, our pollution or environmental

bad measure is a dependent variable and in others it is an explanatory variable. This measure is discussed in detail below. 


\section{Explanatory Variables}

Most gold worldwide is mined from lode deposits (concentrated deposits contained within surrounding rock). A very small proportion of the world's gold is mined from placer deposits, in which gold is contained in alluvial deposits produced from water or ice. Because they use such widely different technologies and extraction processes in comparison to underground and open pit mines, placer mines were excluded from the analysis. In this study, we measure environmental efficiency in both open pit and underground mines. We control for each type of mining process in the analysis.

Open pit (surface) mines usually involve extensive blasting away of vegetation, soil, and rock with explosives to gain access to lode deposits. This type of mining also involves the construction of benches into the walls of the mine to access ore deposits further down on the surface. Underground mining, in contrast, requires that a shaft be sunk into the ground to reach the ore body, which is accessed by "drifts" (passages) that are cut from the shaft at different depths. In our sample, 218 mines are underground (UNDERGROUND) and 201 are open mines (OPENPIT). We adjust for each type of mine operation in the analysis by including OPENPIT as an explanatory variable and interacting it with all other explanatory variables. A few mines had both open pit and underground operations. In these cases, the open pit operations were often a precursor stage to underground operations. Hence we classified them as underground operations. Econometric tests indicated that this classification was appropriate (i.e. the third dummy variable for mines with both underground and open pit operations had a coefficient which was statistically indistinguishable from the coefficient on the UNDERGROUND dummy and, accordinly, we collapsed these two categories together).

Waste pollution in a gold mining operation conventionally comprises two main types of waste: waste rock and tailings. Waste rock is produced at the extraction stage, where the rock in which the ore is embedded is taken from the ground. Mineral extraction from the mined rock usually involves removing any overburden (e.g. soils, trees), and then drilling, blasting and mucking (removing) the broken ore from the mine (EPA 1995). This stage produces a considerable amount of waste rock, as well as overburden. In addition, it can produce a range of different waste pollutants (ground, air and water) from the large amount of hydraulic fluid, lubricants and associated chemicals (e.g. benzene) involved in the drilling, blasting, mucking and breaking up of ore and its subsequent transport. Other environmental impacts of the extraction stage include: deforestation and habitat loss from site preparation, blasting, and transport networks, soil erosion, dust, air and water pollution (e.g. mercury emissions), structural damages due to vibration and settling and impacts arising from other land uses which may be displaced by the mining operations. These impacts are hard to quantify and are not investigated in our analysis.

The second stage, known as beneficiation, involves the processing of the ore using physical and chemical means in order to regulate its size, to remove unwanted constituents and/or improve its

quality (EPA 1995). It is this ore which is eventually processed to produce gold and tailings (unspent and low grade ore). A number of methods are used to beneficiate the ore but virtually all involve the application of cyanide (sodium cyanide or potassium cyanide), to expose the metal values in the 
ore to the cyanide (the leaching stage). The gold is then precipitated from the solution to separate it from the remaining chemical and ore. This unspent and economically unprofitable ore is then stored in dumps or ponds, possibly for reprocessing later. In addition to large volumes of residual and gold metal-cyanide complexes, other waste will also be emitted at this stage, for example, heavy metals and chemicals such as sulfuric acid, and mercury acetylene.

In gold mining, the share of the originally extracted gold ore that ends up as low grade and spent ore (excluding overburden) is as high as $99.99 \%$, compared to iron at $60 \%$ and Aluminium at $70 \%$ (Gardner and Sampat 1998). Since the gold that is eventually produced comprises only a small part of the ore (measured in mere grams per tonne) the remainder of the ore (spent ore and low grade ore) is treated as waste or "tailings". In this study, our environmental "bad" measure is these tailings (TAILINGS), a measure for which we have data for all mines. TAILINGS is measured in millions of tonnes. Note that while tailings are comprised overwhelmingly of the waste geological material created at the beneficiation stage, they may, as mentioned, also contain many other pollutants (e.g. metalcyanide complexes). Thus, tailings waste can be thought of as an indirect measure of the potential scale of production of these other, non-geological or chemical wastes, on the environment. That is, while there is no direct correlation between tailings production and chemical use, in general the more of such solid waste produced the more chemicals needed, ceteris paribus. This has particularly been the case for the gold mining industry over the past decade or so (the period of our data set). In general, ore grades have declined over this period, with the consequence that chemicals use has increased. ${ }^{2}$

Tailings waste comprises a widespread environmental management problem in the gold mining industry today. Its existence also presents (as does waste rock and overburden) a large economic burden for mines. Firms will expend considerable effort in minimizing the cost of its disposal and storage (IIED 2002). One management problem is simply where to put the sheer volume of such waste produced (IIED 2002). Tailings are usually dumped in piles or ponds ("dams"), or in specially made storage facilities. Backfilling of waste in open cast mines is another way of dealing with the storage problem. The impacts on the land around and beyond the site of the mining operation are directly related to the volume of waste produced. The huge volumes of tailings that must either be stored or disposed of has immense negative implications for plant and wildlife populations, forests, and the amenity value of the landscape.

Tailings waste also poses significant management problems as a pollutant, when it is stored or disposed of in the environment. This relates to the fact that this material is often in and of itself quite toxic, but it is also rendered further as such by its processing. For example, gold tailings often contains high levels of dangerous substances such as heavy metals and from the processing stage, added deadly chemicals (e.g. cyanide). These pollutants can find their way into the air, ground and water systems, with potentially detrimental consequences for flora and fauna. In addition, water systems can be affected simply as a result of the reduction in groundwater recharge due to increased run-off from fine particles in the waste. A major concern of tailings waste is its chemical instability, leading to transformation of its constituent components and their dispersion in the environment. For example, since they are highly erodible in water, tailings have great potential to impact negatively on water 
supplies through the production of acids and dissolved metals. The remediation of acid drainage is a particularly costly process for firms. Costs are compounded by the acid's long-term presence in the environment, and its serious and direct impact on waterways. Acidic water also can generate new pollutants, such as dissolved metals (e.g. aluminium and copper). Their presence in the water can lead to a slimy substance (ochre) that is detrimental to aquatic life.

Moreover, the transport of tailings waste to dump sites - by rail cars, trucks, conveyors, and elevators - also creates hazardous emissions and is highly energy intensive. The construction of ponds and other forms of storage also requires immense amount of water. Dust (which can contain high levels of toxic materials such as silica and arsenic) from the dry beaches of tailings storage facilities is also of major concern, particularly in arid areas. In recent years, there has been a wide number of failings in tailings storage. Some of these disasters have left huge environmental footprints. To give but one example from our own data set: A failing in 1995 in the tailings dam at the Omai mine in Guyana (owned by the Canadian multinational Cambior, Inc.) resulted in the release of hundreds of millions of gallons of cyanide-laced tailings slurry into a river that feeds the country's main waterway, killing tens of thousands of birds and aquatic animals (UNEP 2002). (For a comprehensive list of recent tailings storage failures see Engels 2002-2006).

We also control in the analysis for other factors that may have a potential effect on output. The location and size of gold ore deposit depends on complex geological factors, which are not distributed uniformly in the world. Among the set of feasible locations in the world, the multinational firm will evaluate both the geological and geotechnical characteristics of a site in order to determine the economic feasibility of developing a mine. The initial decision to develop a mine will be influenced greatly by these characteristics (e.g. deposit shape and location, scale grains of the ore mineral, hardness, impurities, steepness of open pits, stability of underground openings of the site and so forth). These characteristics will to a large extent determine the economic feasibility of developing a mine. Among these economically feasible possibilities, only a handful of mines will be developed at any given point in time. Geological and geotechnical characteristics, while important from a production standpoint, largely figure at the mine location decision and pre-operational stage. Moreover, to a certain extent, the type of mining method adopted will indirectly reflect these characteristics. Geological models of the ore body, mineral grades and tonnages, for example, will all determine whether the mine will be mined as open pit or underground (IIED 2002). Hence, our OPENPIT explanatory variable will partly capture geological characteristics.

We also include the two geological characteristcs which are most important to production: RESOURCES and GRADE. To a far greater degree than other geological and geotechnical factors, these two measures will have an influence on mine performance. That is, they will also impact on the mine after the decision to develop it is made, at the operations stage, which is the focus of our analysis. In this study, our variable RESOURCES measures (in units of millions of tonnes) the concentration or occurrence of the metal in a form and quantity that there are reasonable prospects for its eventual economic extraction. In other words, it provides a measure of the total concentration of the resource of economic interest and includes the following categories (in order of increasing geological confidence): 
inferred, indicated and measured. It also includes all probable and proven ore reserves (measured in millions of tonnes). (A reserve represents only that part of the resource that can be profitably extracted at a given point in time, under current technical and market conditions). We use the comprehensive "resources" measure rather than the "reserves" measure since it is the former that fully specifies the method of mining adopted, and thus, the degree of waste produced and any technological and other investments made in the mine over the years of operation. GRADE is measured as grade of gold in the ore body (in units of grams per tonne). Grade of ore will have a direct impact on the amount of waste produced. For example, low grade, disseminated ore bodies tend to produce more waste than higher grade ores since they are usually mined using open pit methods. Open-pit mines generally produce more waste than underground mines. GRADE is measured as the amount of contained gold in the ore in grams/tonne.

We also control for mine ownership and country income level. These variables allow us to proxy possible pollution haven behavior among the multinational firms in addition to allowing us to make comparisons between domestic and foreign firms operating in the same country. Data for country income levels was obtained from the World Bank 2001. Countries are classified according to World Bank definitions of low, lower-middle, upper middle and high GNP per capita. These income categories have been conflated in a dummy variable reflecting: a) low to lower-middle income $(\$ 0-\$ 2995)$ and b) upper middle to high income countries $(>\$ 2996)$. These country income distinctions are captured by the dummy variable, RICH ( $1=$ rich; $0=$ poor). Our measure of foreign influence relates specifically to the issue of control (as opposed to ownership); that is, to who makes decisions over production. We measure ownership using the so-called normal method. The normal method of inferring ownership attributes all production from the producers (mines) to controlling companies rather than to the shareholders ('equity share' method). For example, if a company holds $70 \%$ in a mining company and the remaining $30 \%$ of the shares are small shareholders only, it is designated to have $100 \%$ control. If this controller is a foreign company (i.e. has its head office in a country outside of where it is operating), then our variable FOREIGN assigns it a value of 1 ; and 0 , if domestically controlled. Where there is control by both domestic and foreign firms, the mine is classified as FOREIGN. This way of measuring foreign influence is realistic in that generally it is these controlling companies that make the decisions about where to locate, what production methods to adopt, and so forth. In contrast, the owner(s) or shareholders do not generally exert any influence over such decisions. As an aside, we note that we are using the familiar term "ownership" in our discussion, but it would be more formally correct to call this "controllership".

Finally, we have not mentioned conventional inputs such as capital and labor since for many mines data are missing and hence including them would reduce sample size. In the next section, we discuss some results including variables for capital and labor in a subset of mines for which such data were available. We present evidence that indicates that it is better not to include these variables (and, thus, work with a much larger data). In this subset analysis, capital (CAPITAL) is measured in terms of project costs, defined as the initial startup cost for the mine, in millions of US dollars. Labour (LABOR) is measured as the number of permanent employees in each mine. 


\section{Empirical Results}

We have shown how there are many ways of measuring efficiency with multiple output production. When some of the outputs are undesirable and we are interested in measuring both environmental and technical efficiency, the number of possible efficiency measures multiplies. Hence rather than select a single way of measuring technical and environmental efficiency, we present an array of results using different metrics. After all, an empirical result that is found repeatedly using different methods is more believable than one found using only one. We begin with some benchmark results, obtained from standard single-output panel data stochastic frontier models (where the bad output, TAILINGS, is treated as an input). We then present results using the multiple-equation approach based on Fernández, Koop and Steel (2000).

The production frontier in all of our approaches takes a translog form in the set of explanatory variables. The set of explanatory variables always includes GRADE, RESOURCES and OPENPIT. When environmental efficiency is estimated with TAILINGS treated as an input, TAILINGS is an explanatory variable. Based on preliminary econometric analysis, there does not seem to be evidence of variation over time in either the production frontier or mine-specific inefficiencies. Accordingly, we do not include a time effect in our model.

To address some of the key policy questions of interest in this paper, it is important to see whether the efficiencies of mines can be associated with any explanatory variables. For instance, if mines in poor countries are less technically or environmentally efficient than those in rich countries, then this may suggest that mines are less careful about the environment in poor countries. Similarly, if foreignowned firms are found to be less environmentally efficient than domestically-owned firms, that suggests rich country multinationals are behaving environmentally worse than domestic firms. As described in Appendix A, our econometric models allow for explanatory variables in the inefficiency distribution. We let $w_{i j}$ for $i=1, . ., N$ and $j=1, . ., m$ denote the value of the $j^{t h}$ explanatory variable for the $i^{t h}$ mine and allow for an intercept (i.e. $w_{i 1}=1$ for all mines). In our empirical work, all of the other explanatory variables in the inefficiency distribution are dummy variables. We allow for them to affect the mean of the inefficiency distribution ${ }^{3}$ as:

$$
\lambda_{i}^{-1}=\prod_{j=1}^{m} \phi_{j}^{w_{i j}},
$$

where $\lambda_{i}$ is the mean of the inefficiency distribution of mine $i$ and $\phi_{j}>0$ for $j=1, . ., m$. To aid in interpretation note that if $\phi_{j}=1$ for $j=2, \ldots, m$ then this model reduces to one with no explanatory variables in the efficiency distribution (i.e. $\lambda_{i}^{-1}=\phi_{1}$ which is the same for all mines). If, for instance, $w_{i 2}$ equals one for foreign-owned mines (and zero for domestically-owned mines), then (6) allows for these two types of mines to have different inefficiency distributions (i.e. $\lambda_{i}^{-1}=\phi_{1} \phi_{2}$ for foreign-owned

mines and $\lambda_{i}^{-1}=\phi_{1}$ for domestically-owned mines). If $\phi_{2}>1$ then the mean of the inefficiency distribution is lower for foreign-owned firms. Thus, if $\phi_{2}>1$, foreign-owned firms tend to be more efficient than domestically-owned ones (i.e. lower inefficiency means higher efficiency). We stress that 
such a finding would not imply that every foreign-owned firm is more efficient than every domesticallyowned one, but rather that the former are drawing their efficiencies from a distribution with a higher mean. Overall, if $\phi_{2}>1$ it will be evidence that foreign-owned firms do tend to be more efficient than domestically-owned ones. Similarly, $\phi_{2}<1$ indicates that domestically-owned mines are more efficient than foreign-owned ones. If $\phi_{2}=1$ foreign- and domestically-owned forms tend to have the same efficiency. This motivates an interest in the hypothesis that $\phi_{2}=1$ and we can calculate the probability that this hypothesis is true as described in Appendix A. The previous discussion relates to $\phi_{2}$. Similar considerations hold for $\phi_{j}$ for $j=3, \ldots, m$. In our empirical work, we use two dummy explanatory variables in the inefficiency distribution: FOREIGN and RICH.

\section{Single Output Results}

We begin by presenting some results using stochastic frontier models with a single output and TAILINGS included as an input (and all other explanatory variables listed above). All variables (except dummy variables) are logged in our translog specification. As noted, we consider two different possibilities for the single output: the (log of) gold output (AU) and the (log of) the total value of gold, silver and copper produced (AU, AG and CU) by each mine (measured in millions of US dollars).

Although we are mostly interested in mine efficiency, it is of interest to present some results relating to the production frontier itself (if only to establish that it is reasonable). Table 2 presents point estimates (i.e. posterior means) and associated measures of uncertainty (i.e. posterior standard deviations) for the coefficients in our translog production frontier. Loosely speaking, the specifications in table 2 are similar to a traditional random effects specification (i.e. the inefficiency term plays the role of the individual effect) and the non-Bayesian reader may prefer to interpret them in this manner (i.e. as being very similar to what the random effects estimator of the translog production frontier would produce). Note that in our discussion we will use an informal rule of thumb that says that a posterior mean two/one standard deviations from zero indicates strong/weak evidence that the corresponding variable has explanatory power for the dependent variable.

The point estimates in table 2 are mostly sensible. For instance, there is strong evidence that TAILINGS is an important explanatory variable that is positively associated with output. Other important explanatory variables include GRADE and RESOURCES. There is strong evidence that GRADE is positively associated with output, but slightly less evidence for RESOURCES. An important issue is whether open pit mines have a different technology than other mines. Unsurprisingly, we are finding they do. There is only weak evidence of a direct effect of OPENPIT on output. But there is strong evidence that some of the interaction terms (e.g. TAILINGS $\times$ OPENPIT) have such an effect. There is strong evidence that some of the interaction and squared terms are important explanatory variables, indicating that a translog specification is necessary to model mining technology. Finally, although there are some differences between results obtained using gold output as the dependent variable and those obtained using a dependent variable measured as the value of all metals, overall the two estimated frontiers are sensible and similar. 
table 2 here

Table 3 presents results relating to $\phi_{j}$, the coefficients on the explanatory variables in the inefficiency distribution. The point estimates of the coefficients on the foreign-owned and developed-country variables are both greater than one (regardless of which dependent variable is used). This indicates that foreign-owned and/or developed country mines do tend to be more efficient than domesticallyowned and/or developing-country mines. However, the uncertainty associated with the point estimate is large, and table 3 indicates that the probability of the coefficients equalling one is quite high. Thus, it seems that there are no systematic differences in efficiency across these different categories of mine.

table 3 here

For the sake of brevity, we do not produce results relating to technical (calculated using equation 2) and environmental efficiency (calculated using the input-oriented efficiency measure of equation 4 for the input TAILINGS) for every one of our 419 mines. As an example, let us present some results relating to Barrick, the world's third largest gold mining company. A large Canadian multinational, Barrick has mines around the world, including some in rich countries (i.e. the Betze Post Gold Mine and Meikle Gold Mines in the USA) and some in poor countries (i.e. the Porgera Gold Mine in PapuaNew Guinea and the Pierina Gold Mine in Peru). It would be interesting to see if their operations are very different in developed and developing countries. Using our model where the value of all metals is the dependent variable (results using gold only are similar), Table 4 presents posterior means and standard deviations for technical and environmental efficiency for four Barrick mines. Based on an examination of point estimates, it seems that three of the mines (Pieria, Betze Post and Meikle) have efficiencies that are basically the same as one another. This holds regardless of whether we are talking about technical or environmental efficiency. The Porgera mine has slightly lower point estimates of efficiencies. However, an examination of the posterior standard deviations indicates that the differences in point estimates are very small. In short, the story coming out of table 4 is the same as that from table 3. An examination only of point estimates indicates that mines operating in rich are slightly more efficient than those operating in poor countries, but this difference is negligible relative to the uncertainty in the point estimates (i.e. differences in posterior means are very small relative to posterior standard deviations).

table 4 here

The previous discussion suggests that we need to interpret efficiency point estimates with caution, since their posterior standard deviations can be quite large. With this warning in mind, figures 1 and 2 are histograms of the point estimates of environmental efficiency for each mine for rich and poor countries, respectively, ${ }^{4}$ using the same models as for table 4 . If we simply average the point 
estimates of all mines in developed countries we obtain an average efficiency of 0.68 . The same number is obtained for poor countries. On the whole, the spread of efficiencies in these two figures is similar. Rich countries have a very small number of mines that are extremely environmentally inefficient (e.g. point estimates of efficiency of around 0.1) which does not occur for the developing countries. However, poor countries have more mines that seem moderately inefficient (e.g. efficiencies between 0.3 and 0.4 ). But, overall, figures 1 and 2 are quite similar. Using single-output stochastic frontier methods, we consistently find that there are no systematic differences in environmental efficiency between mines operating in poor and rich countries (or between foreign and domestically-owned mines).

figures $1 \& 2$ here

It is also worth mentioning that we estimated these models using the same translog production frontier described above, except that we included as inputs measures of capital (CAPITAL) and labour (LABOR). Due to missing value problems, this massively reduced our data set to 351 observations involving only 54 mines (as opposed to the 2211 observations on 419 mines used to produce the tables and figures above). With a data set of this size, it is difficult to obtain precise estimates of parameters or efficiencies. However, the point estimates of $\phi_{2}$ and $\phi_{3}$ are similar to those found above, but their posterior standard deviations were much larger. In this and other ways, the main findings noted above are unaffected by incorporating CAPITAL and LABOR as explanatory variables (i.e. there is no evidence of any systematic differences in environmental or in technical efficiency between mines in rich and poor countries or between foreign and domestically controlled mines). We take this as some evidence that the explanatory variables listed in Table 2 are adequate to approximate the production frontier in our data set.

\section{Multiple Output Results}

The results in the previous section are suggestive, but either ignore the multiple output nature of gold production or impose a particular shape to the output aggregator, $g($.$) (i.e. by calculating the value of$ metal produced we are using metal prices to construct $g($.$) ). However, we can also estimate g($.$) from$ the data. This is what we do in this section. Details of the econometric methods used are provided in Appendix A, using a constant elasticity of substitution form for $g($.$) . Our first set of results assumes$ there are three good outputs (gold, copper and silver) and the bad output, TAILINGS, is treated as an input. As a measure of technical efficiency we use a gold-oriented measure (see equation 5 and the discussion that follows for a motivation) and the input-oriented efficiency associated with the bad as a measure of environmental efficiency (see equation 4).

For the sake of brevity, we do not provide complete results for this specification for the reason that they are very similar to the single output results. For instance, the frontier has a similar shape as described in table 2, and the efficiencies are similar to those plotted in figures 1 and 2 . As to the issue of whether efficiencies differ depending on whether mines are domestic/foreign-owned or are in a 
rich/poor country, we obtain the same finding as before: there do not seem to be systematic differences between these categories of mines. As evidence of this, table 5 presents estimates of the coefficients in the inefficiency distribution as well as the probability that they equal one. Similar to table 3, point estimates of the coefficients on FOREIGN and RICH variables are slightly above 1 (indicating foreignowned and/or rich country mines are slightly more efficient than others) but these point estimates are so close to one that the hypothesis that they equal one is supported by the data. As an example of the kinds of findings implied by table 5 , the average of the point estimates of environmental efficiency for all mines in rich countries is $\mathbf{0 . 7 5}$, but for poor countries it is 0.69 . For foreign controlled and domestically controlled mines the numbers are 0.74 and 0.73 , respectively. Thus, we are finding point estimates slightly higher in foreign controlled and/or rich country mines, but relative to posterior standard deviations these differences are small.

table 5 here

Our second set of results treats takes an inverse transformation of the bad output and treats it as a good output (see section 2.2). Once again, the results using this specification are very similar to those above. For the sake of brevity, we do not present results for this approach other than those in the right-hand columns of table 5. As with all our specifications, there is no evidence for our variables FOREIGN and RICH having any explanatory power for efficiency.

\section{Conclusions}

In this paper we have sought to determine whether there are any differences in the environmental performance of gold mining firms that operate in poor as opposed to rich countries. We also examined whether foreign controlled gold mines pollute more or less than their domestic counterparts. We have investigated these issues using Bayesian stochastic frontier methods, paying particular attention to the multiple output nature of gold production and the fact that gold mining produces immense amounts of waste pollution. We have presented alternative ways of measuring technical and environmental efficiency and investigated whether they can be related to mine characteristics such as whether the mine is foreign or domestic controlled or whether it is located in a rich vs. a poor country.

This exercise was motivated by the question of whether there are pollution havens in the multinational gold mining industry. Rather than examine the location decisions of these multinational firms in an attempt to infer a posteriori whether they may have gone to poor countries to avoid high environmental compliance costs at home, we focus instead on the actual performance of individual mines in the multinational firm once they have "set up shop". We argued that this kind of analysis avoids potential measurement problems associated with the lack of effective monitoring and enforcement of environmental regulations in developing countries. While some poor countries have fairly strong environmental regulations on the books, the failure to monitor firm behavior may mean that for all intents and purposes such regulations provide no effective disincentive for a firm to avoid 
locating there. Moreover, our data set allows us to measure the waste produced directly by each mine, in the country in which it is produced. This is in opposition to studies that use disparate and largely irrelevant (for the firm, at least) environmental regulations (e.g. lead content limits in gasoline), or assume one aggregate measure of pollution (e.g. national $\mathrm{SO}^{2}$ emissions) reflects aequately the degree of environmental stringency facing a firm seeking to set up operations in a country.

We find that, regardless of whether we treat our waste measure as an input or a bad output, we obtain qualitatively similar results. Regardless of whether we use gold, the value of all metals or estimate a multiple-output production possibility curve from the data, we obtain qualitatively similar results. For our policy questions of interest, our key (and very robust) finding is that there is no evidence of any systematic differences in environmental or technical efficiency between mines in rich vs. poor countries or between foreign vs. domestic owned mines.

While we find that there are no statistically significant variations in performance between these different categories, we caution that this may not be the case if a fuller picture of the environmental impacts of gold mining were to be examined. Some environmental impacts were not measured directly in this study (e.g. our tailings measure includes things like cyanide but we do not have a precise measure of how much cyanide) but are often regulated. Others are difficult to measure because they remain unregulated do not exist. Still, for others, the nature and magnitude of their impact may vary so greatly with the carrying and absorptive capacities of the home environment as to render a statistical comparison meaningless. Nevertheless, the fact that there are no real appreciable differences in the environmental performance of gold mining firms operating around the world in respect to our pollution measure (which depends to a far lesser extent on country ecology and whose volume can be linked to environmental impact to a far greater degree than other waste pollution) suggests that there may be environmental similarities underlying gold mining operations worldwide.

This is not to say that multinational gold mining firms are not creating substantial amounts of waste pollution, only that they are not producing appreciably more of it in poor than in rich countries. Indeed, they are neither appreciably underperforming or overperforming in comparison to domestic firms. Hence the empirical evidence of this study confirms the conclusions of most other industry/firm and plant level studies of manufacturing industries: Foreign multinationals are not flocking to poor countries or regions due to the relative laxity of their environmental regulations.

In short, the impact of environmental regulations on firm performance in the gold mining industry is not best described by our research as one dominated by pollution havens. Pollution and environmental degradation have been a large part of the industry since its inception. These impacts continue to be huge, in rich and poor countries alike. This, despite technical innovations that have raised productivity and the adoption by firms of increasingly strict "rich country" environmental codes. But, even in countries where such regulation is weak or lacking, mining companies appear to be adhering to the strictest self-regulation as currently defined by richer country regulations. Moreover, domestic companies appear to be emulating them, at least with respect to our measured environmental indicator. Whether this standard of environmental behavior is socially optimal or not is another question. If it is not, as many believe, then the more relevant policy question may not be whether pollution 
havens exist at all, but whether regulatory chill best describes the context in which the global mining industry operates. In this respect, we hasten to add that we are not talking about regulatory chill as it has been described to exist only in poor countries. Rather, we are talking about the possibility of a "global regulatory chill", a standard of performance defined by the richest country to which all firms are adhering worldwide. Thus, the more relevant question for regulatory policy may be: If environmental performance can indeed be raised with the current level of technology, what aspects of the institutional context of rich countries has prevented it from happening? The next question then becomes: What kind of intervention will lead to a rise in environmenal performance worldwide? 


\section{References}

Adams, R., Berger, A. and R. Sickles. 1999. "Semiparametric Approaches to Stochastic Panel Frontiers with Applications in the Banking Industry." Journal of Business and Economic Statistics 17(3): 349-358.

Atkinson, S. and J. Dorfman. 2005. "Bayesian Measurement of Productivity and Efficiency in the Presence of Undesirable Outputs: Crediting Electric Utilities for Reducing Air Pollution." Journal of Econometrics 126:445-468.

Baumol, W., and W.E. Oates. 1988. The Theory of Environmental Policy. New Jersey: Prentice Hall.

Becker, R. and V. Henderson. 2000. "Effects of Air Quality Regulations on Polluting Industries." Journal of Political Economy 108:379-421.

Birdsall, N., and D. Wheeler. 1993. "Trade Policy and Industrial Pollution in Latin America: Where are the Pollution Havens?" Journal of Environment and Development 2:137-149.

Boyd, G. 1987. "Factor Intensity and Site Geology as Determinants of Returns to Scale in Coal Mining." Review of Economics and Statistics 69(1):18-23.

Cairns, R. 1981. "An Application of Depletion Theory to a Base Metal: Canadian Nickel." Canadian Journal of Economics 14:635-648.

Caves, D.E., Christensen, L. and W.E. Diewert. 1982. "The Economic Theory of Index Numbers and the Measurement of Input, Output and Productivity." Econometrica 50(6):1393-1414.

Cropper, M. and W.E. Oates. 1992. "Environmental Economics: A Survey." Journal of Economic Literature 30:675-740.

Dean, J.M., M.E. Lovely, and H. Wang. 2004. "Foreign Direct Investment and Pollution Havens: Evaluating the Evidence from China." Working Paper 2004-01B, US International Trade Commission. Available at: http://hotdocs.usitc.gov/docs/pubs/research_working_papers/EC200401B.pdf.

Ederington, J., A. Levinson, and J. Minier. 2005. "Footloose and Pollution-Free." The Review of Economics and Statistics 87(1):92-99.

Engles, J. 2002-2006. "Tailings Related Accidents - Failures, Breaches and Mudflows." Available at: http://www.tailings.info/accidents.htm.

EPA (US Environmental Protection Agency). 1995. Profile of the Metal Mining Industry. EPA Office of Compliance Sector Notebook Project. Office of Compliance. Washington, D.C.: Office of Enforcement and Compliance Assurance.

Eskeland, G.S. and A.E. Harrison. 2003. "Moving to Greener Pastures? Multinationals and the Pollution Haven Hypothesis." Journal of Development Economics 70(1):1-23.

Esty, D. C. and D. Geradin. 2001. "Regulatory Competition.". In Regulatory Competition and Economic Integration: Comparative Perspectives. D. C. Esty and D. Geradin, eds. Oxford: Oxford University Press.

Fare, R., S. Grosskopf, D-W. Noh, and W. Weber. 2005. "Characteristics of a Polluting Technology: Theory and Practice." Journal of Econometrics 126(2): 469-492. 
Fare, R. and D. Primont. 1995. Multi-output Production and Duality: Theory and Applications. Boston: Kluwer Co.

Farrow, S. 1985. "Testing the Efficiency of Extraction from a Stock Resource." Journal of Political Economy 93: 452-487.

Fernández, C., G. Koop, and M.F.J. Steel. 2000. "A Bayesian Analysis of Multiple-output Production Frontiers." Journal of Econometrics 98(1): 47-49.

Fernández, C., Koop, G. and M.F.J. Steel. 2002. "Multiple-output Production with Undesirable Outputs: An Application to Nitrogen Surplus in Agriculture." Journal of the American Statistical Association 97:432-442.

Fernández, C., Koop, G. and M.F.J. Steel. 2005. "Alternative Efficiency Measures for MultipleOutput Production." Journal of Econometrics 126(2):411-444.

Friedman, J., D.A. Gerlowski, and J. Silberman. 1992. "What Attracts Foreign Multinational Corporations? Evidence from Branch Plant Locations in the United States." Journal of Regional Science. 32(4):403-418.

Gardner, G., and P. Sampat. 1998. Mind Over Matter: Recasting the Role of Materials in Our Lives. Worldwatch Paper 144, Worldwatch Institute.Washington, DC: Worldwatch Institute.

Greenstone, M. 2002. "The Impacts of Environmental Regulations on Industrial Activity: Evidence from the 1970 and 1977 Clean Air Act Amendments and the Census of Manufactures." Journal of Political Economy 110:1175-1219.

Grossman, G E. and A. B. Krueger.1993. "Environmental Impacts of a North American Free Trade Agreement." In P. Garber, ed. The Mexico-U.S. Free Trade Agreement. Massachusetts: M.I.T Press.

Horrace, W. and P. Schmidt. 1996. "Confidence Statements for Efficiency Estimates From Stochastic Frontier Models." Journal of Productivity Analysis 7:257-282.

IIED (International Institute for Environment and Development). 2002. Mining for the Future: Appendix A: Large Volume Waste. Working Paper 31. Mining, Minerals and Sustainable Development Project, IIED.

Keller, W. and A. Levinson. 2002. "Pollution Abatement Costs and Foreign Direct Investment Inflows to the U.S. States." Review of Economics and Statistics 84: 691-703.

Koop, G. 1998. "Carbon Dioxide Emissions and Economic Growth: A Structural Approach." Journal of Applied Statistics 25: 489-515.

Koop, G., J. Osiewalski, and M.F.J. Steel. 1997. "Bayesian Efficiency Analysis Through Individual Effects: Hospital Cost Frontiers." Journal of Econometrics 76(1): 77-105.

Koop, G. and M.F.J. Steel. 2001. "Bayesian Analysis of Stochastic Frontier Models." In B. Baltagi, ed. A Companion to Theoretical Econometrics. Oxford: Blackwell Publishers, pp. 52-537.

Lasserre, P. 1985. "Capacity Choice by Mines." Canadian Journal of Economics 18: 831-842.

Lasserre, P. and P. Ouellette. 1988. "On Measuring and Comparing Total Factor Productivities in Extractive and Non-extractive Sectors." Canadian Journal of Economics 21: 826-834.

Levinson, A. 1996. "Environmental Regulations and Manufacturers' Location Choices. " Journal of Public Economics 62: 5-29. 
List, J. and C.Y. Co. 2000. "The Effect of Environmental Regulation on Foreign Direct Investment." Journal of Environmental Economics and Management 40:1-40.

List, J., D.J. Millimet, P. Fredriksson, and W. McHone. 2003. "Effects of Environmental Regulations on Manufacturing Plant Births: Evidence From a Propensity Score Matching Estimator." Review of Economics \& Statistics 84:944-952.

Löthgren, M. 1997. "Generalized Stochastic Frontier Production Models." Economics Letters 57:255-259.

Low, P., and A. Yeats. 1992. "Do Dirty Industries Migrate?" In P. Low. ed. International Trade and the Environment. World Bank, Discussion Paper 159. Washington, D.C.: World Bank.

McConnell, V. D. and R.M. Schwab. 1990. "The Impact of Environmental Regulation on Industry Location Decisions: The Motor Vehicle Industry." Land Economics 66:67-81.

Neumayer, E. 2001. Greening Trade and Investment: Environmental Protection Without Protectionism. Earthscan Publications Ltd: London.

New York Times. 2004. "Mining Giant was Warned on Pollution in Indonesia." December 22nd.

New York Times. 2005a. "Below a Mountain of Wealth, a River of Pollution." December 27th.

New York Times. 2005b. "The Cost of Gold." October 24th-25th.

New York Times. 2005c. "Behind Gold's Glitter: Torn Lands and Pointed Questions." October 24 th.

New York Times. 2006a. "Gold Mining Company to Pay Indonesia $\$ 30$ Million." February 17th.

New York Times. 2006b. "Indonesia Says Pollution From Mine Tainted Fish." February 4th.

Nordström, H. and S. Vaughan. 1999. "Special Studies: Trade and Environment." World Trade Organization. Available at http://www.wto.org/ link.

Pittman, R. 1981. "Issues in Pollution Control: Interplant Cost Differences and Economies of Scale." Land Economics 57:1-17.

Pittman, R. 1983. "Multilateral Productivity Comparisons with Undesirable Outputs." Economic Journal 93:883-891.

Poirier, D. 1995. Intermediate Statistics and Econometrics. Cambridge: MIT Press.

Reinhard, S., C.A.K. Lovell,. and G. Thijssen. 1999. "Econometric Application of Technical and Environmental Efficiency: An Application to Dutch Dairy Farms." American Journal of Agricultural Economics 81:44-60.

Shephard, R.W. 1970. Theory of Cost and Production Functions. Princeton, New Jersey: Princeton University Press.

Simar, L. and P. Wilson. 1998. "Sensitivity Analysis of Efficiency Scores: How to Bootstrap in Nonparametric Frontier Models." Management Science 44:49-61.

Smarzynksa, B.K., and S-J. Wei. 2001. "Pollution Havens and Foreign Direct Investment: Dirty Secret or Popular Myth?" Working Paper 8465, National Bureau of Economic Research (NBER).

Tyteca, D. 1996. "On the Measurement of the Environmental Performance of Firms: A Literature Review and a Productive Efficiency Perspective." Journal of Environmental Management 46:281-308. 
UNEP 2002. "Environment." Mineral Resources Forum. Available at: http://www.mineralresources forum.org/incidents/Omai/index.htm.

World Bank. 2001. World Development Indicators. Washington, D.C: The World Bank.

Young, D. 1992. "Cost Specification and Firm Behaviour in a Hotelling Model of Resource Extraction." Canadian Journal of Economics 25:41-59.

Zarsky, L. 1997 "Stuck in the Mud? Nation States, Globalisation and Environment." In Globalisation and Environment: Preliminary Perspectives. Paris: OECD.

Zarsky, L. 1999. "Havens, Halos and Spaghetti: Untangling the Evidence about Foreign Direct Investment and the Environment." Paper Presented at the Conference on Foreign Direct Investment and the Environment. OECD Environment Directorate. Available at: http://www.nautilus.org/papers/ enviro/zarsky_oecdfdi.html. 


\section{Appendix A: Econometric Methods}

In this appendix, we describe our Bayesian econometric methods. Motivation for this approach is provided in previous work (e.g. Koop, Osiewalski and Steel, 1997). Advantages include the fact that exact finite sample properties of all features of interest can easily be obtained. For instance, Bayesian posterior standard deviations or credible intervals (i.e. the Bayesian analogue to standard errors and confidence intervals) for mine-specific efficiency are obtained immediately. Given that firm-specific efficiencies can be imprecisely estimated in many empirical contexts, we argue that presenting a measure of the uncertainty associated with an estimate of mine-specific efficiency is crucial. Standard implementations of DEA or index number approaches to not provide such measures of uncertainty. More sophisticated DEA approaches can calculate confidence intervals using the asymptotically-justified bootstrap. (See, e.g., Simar and Wilson 1998). In classical econometrics, it is also difficult to calculate confidence intervals for efficiencies. Horrace and Schmidt (1996) provides a discussion of various methods for constructing confidence intervals for efficiencies. Note that these involve strong assumptions and treat estimates of parameters as though they are equal to true values.

The Bayesian approach begins with a likelihood function (i.e. a joint distribution for our dependent variables). In our case, this involves specifying a distribution for the good and bad outputs, given the inputs. This is combined with a (relatively noninformative) prior to yield a posterior. The properties of this posterior can be analyzed using Markov Chain Monte Carlo (MCMC) methods. Since these methods have been developed in detail in Fernández, Koop and Steel (2000; 2005), we will not provide all the details here. Rather, in this section, we will provide an outline of the basic ideas; the reader is referred to the previous work for full details.

In this appendix, we begin describe our econometric methods for models based on (2), (3), (4) or (5). The basic notation we use is described in the text (e.g. around equation 1). In our mining application, extensions of basic models of production are required since mines can be quite heterogeneous. Hence, we add the notation $z=\left(z_{1}, . ., z_{s}\right)$ to denote $s$ different geological characteristics of the mine (e.g. ore grades). We will let $i$ denote the $i^{t h}$ mine $(i=1, \ldots, N)$ and $t$ denote the $t^{t h}$ time period $\left(t=1, \ldots, T_{i}\right)$. Note that we have an unbalanced panel and use the notation $N T$ to denote all our observations. The output of a particular mine at a particular point in time is a $p$-dimensional vector

$y_{(i, t)}=\left(y_{(i, t, 1)}, \ldots, y_{(i, t, p)}\right)^{\prime}$, and we assume a constant elasticity of substitution function form for aggregate output can be expressed as:

$$
g\left(y_{(i, t)}\right)=\left(\sum_{j=1}^{p} \alpha_{j}^{q} y_{(i, t, j)}^{q}\right)^{1 / q}
$$

where $q>1, \alpha=\left(\alpha_{1}, \ldots, \alpha_{p}\right)^{\prime}$ with $\alpha_{j} \in(0,1)$ for all $j=1, \ldots, p$ and $\sum_{j=1}^{p} \alpha_{j}=1$. For fixed values of $\alpha$ and $q, g\left(y_{(i, t)}\right)=$ constant defines a production possibility curve, i.e. a $(p-1)$-dimensional surface consisting of all output vectors $y_{(i, t)}$ that are technologically equivalent. Note that the restriction $q>1$ ensures a negative elasticity of transformation between any two outputs. The interpretation of the parameter $\alpha$ in (A1) is to deal with scaling of the outputs, which is, therefore, quite separate from the 
role of elasticity of transformation $q$.

We model the aggregate output $g\left(y_{(i, t)}\right)$ using a conventional stochastic frontier specification. To this end we define $\delta_{(i, t)}=\log \left(g\left(y_{(i, t)}\right)\right)$, define the $N T$-dimensional vector

$$
\delta=\left(\delta_{(1,1)}, \delta_{(1,2)}, \ldots, \delta_{\left(1, T_{1}\right)}, \ldots, \delta_{\left(N, T_{N}\right)}\right)^{\prime} .
$$

The next step is to specify a functional form for the production frontier. Before we do this, we note that the maximum possible production from a mine will depend on its inputs and its geological characteristics and, hence, we replace (1) by

$$
g(y)=h(x, z) .
$$

In our empirical work, we adopt a translog production frontier and, hence, the explanatory variables in our stochastic frontier regression will consist of an intercept and all logged inputs and geological characteristics as well as squares and cross products of these logs. That is, omitting $(i, t)$ subscripts on the $x$ and $z$ variables for notational simplicity, we let:

$$
\begin{aligned}
& \ln [h(x, z)]=\beta_{0}+\sum_{l=1}^{m} \beta_{l}^{x} \ln \left(x_{l}\right)+\sum_{j=1}^{m} \sum_{l \leq j} \beta_{l j}^{x} \ln \left(x_{l}\right) \ln \left(x_{j}\right)+ \\
& \sum_{j=1}^{m} \sum_{l=1}^{s} \beta_{l j}^{x z} \ln \left(x_{j}\right) \ln \left(z_{l}\right)+\sum_{l=1}^{s} \beta_{l}^{z} \ln \left(z_{l}\right)+\sum_{j=1}^{s} \sum_{l \leq j} \beta_{l j}^{z} \ln \left(z_{l}\right) \ln \left(z_{j}\right) .
\end{aligned}
$$

To make the notation compact, let $v\left(x_{(i, t)}, z_{(i, t)}\right)$ be a $k$-dimensional vector containing all these explanatory variables. In matrix notation, we can write a stochastic frontier model using the log of aggregate output as the dependent variable:

$$
\delta=V \beta-\gamma+\varepsilon,
$$

where $V=\left(v\left(x_{(1,1)}, z_{(1,1)}\right), \ldots, v\left(x_{\left(N, T_{N}\right)}, z_{\left(N, T_{N}\right)}\right)\right)^{\prime}$ denotes an $N T \times k$ matrix of translog explanatory variables, $\beta$ is a $k$-vector containing all the regression coefficients in (A3) and $\varepsilon$ is the conventional Normal error which captures the fact that the frontier is not known exactly, but needs to be estimated from the data. Formally, $\varepsilon$ follows an $N T$-dimensional Normal distribution with zero mean and covariance matrix equal to $\sigma^{2} I_{N T}$.

Efficiency considerations arise from the fact that mines may lie below the frontier, thus leading to a vector of deviations between (the log of) actual and maximum possible aggregate output. This vector of deviations is labelled $\gamma$. It is usually reasonable to place some additional structure on these deviations. To this end, we write $\gamma \equiv D u$, where $D$ is a fixed $N T \times M(M \leq N T)$ matrix and $u=\left(z_{1}, \ldots, z_{M}\right)^{\prime}$. Through different choices of $D$, we can accommodate various amounts of structure on the vector $\gamma$ of inefficiencies. For instance, taking $D=I_{N T}$, the $N T$-dimensional identity matrix, leads to an inefficiency term which is specific to each different mine and time period. For a balanced panel, choosing $D=I_{N} \otimes \iota_{T}$, where $\iota_{T}$ is a $T$-dimensional vector of ones and $\otimes$ denotes the Kronecker product, implies inefficiency terms which are specific to each mine, but constant over time (i.e. "individual effects"). In our empirical section we make the latter choice for $D$, but with the obvious extension to unbalanced panels. 
These assumptions lead to a key part of our likelihood function, that which relates to the aggregate output:

$$
p(\delta \mid \beta, u, \sigma)=f_{N}^{N T}\left(\delta \mid V \beta-D u, \sigma^{2} I_{N T}\right),
$$

where $f_{N}^{N T}(. \mid a, A)$ denotes the $N T$-variate Normal density function with mean $a$ and covariance matrix $A$. The model can be completed by assuming an exponential inefficiency distribution. That is, each of the elements of $\gamma$ has an exponential distribution with mean parameter $\lambda$.

For the case of a single output, (A5) is enough to specify the likelihood function and standard Bayesian MCMC methods (e.g. Koop, Osiewalski and Steel, 1997) can be used to carry out Bayesian estimation, inference and model comparison. However, for multiple-output production (A5) is not enough since it is only a single equation but $y_{(i, t)}$ is a $p$-dimensional vector. That is, if we knew what aggregate output was (i.e. if we knew what $\alpha$ and $q$ were), then (A5) would define the likelihood function. However, we wish to estimate at $\alpha$ and $q$ from the data (i.e. we wish to estimate the shape of the production possibility curve rather than assuming a particular shape) and, hence, (A5) alone is inadequate. To express this important concept yet another way, note that (A5) is a model for $\delta$ which merely says what production possibility curve a mine is on. It does not tell us which precise point on the production possibility curve that the mine is operating at.

Following Fernández, Koop and Steel (2000), we complete our model by considering the distribution of the outputs within each of the production possibility curves. A convenient way of doing this, is to obtain a measure which can be interpreted as the share of each individual output in the aggregate:

$$
\eta_{(i, t, j)}=\frac{\alpha_{j}^{q} y_{(i, t, j)}^{q}}{\sum_{l=1}^{p} \alpha_{l}^{q} y_{(i, t, l)}^{q}}, j=1, \ldots, p,
$$

where it can be seen that $0 \leq \eta_{(i, t, j)} \leq 1$ and $\sum_{j=1}^{p} \eta_{(i, t, j)}=1$. To complete the specification of our likelihood, we must specify a distribution for $\eta_{(i, t, j)}$. We adopt a Dirichlet (see, e.g., Poirier, 1995, page 132) distribution which is a flexible and commonly-used distribution to model random variables which are shares.

The exact form of the likelihood function is provided in Fernández, Koop and Steel (2000) and precise details of how Bayesian estimation and model comparison is carried out are provided there. In particular, an MCMC algorithm is developed which provides random posterior draws from all the parameters and for the deviation from the frontier (i.e. $u$ or, equivalently, $\gamma$ ).

Our models allow for explanatory variables in the inefficiency distribution. We do this by extending our previous model to allow for the mean of the inefficiency distribution to dependent on mine characteristics as:

$$
\lambda_{i}^{-1}=\prod_{j=1}^{m} \phi_{j}^{w_{i j}}
$$

where $\lambda_{i}$ is the mean of the $i^{\text {th }}$ element of $\gamma$ (i.e. the deviation from the frontier for mine $i$ ). We let $w_{i j}$ for $i=1, . ., N$ and $j=1, . ., m$ denote the value of the $j^{t h}$ explanatory variable for the $i^{t h}$ mine 
and allow for an intercept (i.e. $w_{i 1}=1$ for all mines). The extension of the MCMC algorithm which allows for (A.7) is described in (A.18) of Fernández, Koop and Steel (2005). As described in the text, the hypothesis that $\phi_{j}=1$ is the hypothesis that the $j^{\text {th }}$ explanatory variable (for $j=2, . ., m$ ) has no effect on the inefficiency distribution. The Bayes factor comparing the model with $\phi_{j}=1$ to $\phi_{j} \neq 1$ can be obtained using the Savage-Dickey density ratio (see Koop and Steel, 2001, for details). The probability that $\phi_{j}=1$ can be obtained from this Bayes factor.

For all our models, we use the same proper but relatively noninformative prior hyperparameter values described in the Appendix to Fernández, Koop and Steel (2005).

The final step required is to link the results from our statistical model defined by (A5) and (A6), with our various measures of efficiency. That is, the statistical model specified in this section will provide us with a posterior for the deviation from the frontier, $\gamma$. We then have to transform this back to provide us with a posterior for the efficiency measures defined in (2), (3), (4) and (5). These transformations are provided in Fernández, Koop and Steel (2005). For simplicity, we drop the $(i, t)$ subscripts in the following equations which should denote that each individual mine in each time period will have a particular efficiency.

For radial output-oriented technical efficiency, $\tau_{R O}$, we have

$$
\tau_{R O}=e^{-\gamma}
$$

For radial input-oriented efficiency, $\tau_{R I}$, we have:

$$
\ln \left(\tau_{R I}\right)=\frac{-b+\sqrt{b^{2}-4 \gamma \sum_{j=1}^{m} \sum_{l \leq j} \beta_{l j}^{x}}}{2 \sum_{j=1}^{m} \sum_{l \leq j} \beta_{l j}^{x}},
$$

where $b=\sum_{l=1}^{m}\left(\beta_{l}^{x}+\sum_{j=1}^{s} \beta_{j l}^{x z} \ln \left(z_{j}\right)\right)+\sum_{j=1}^{m} \sum_{l \leq j} \beta_{l j}^{x} \ln \left(x_{l} x_{j}\right)$ and existence of the solution requires that $b^{2}>4 \gamma \sum_{j=1}^{m} \sum_{l \leq j} \beta_{l j}^{x}$. For input $l$-oriented efficiency, we obtain:

$$
\ln \left(\tau_{I l}\right)=\frac{-e_{l}+\sqrt{e_{l}^{2}-4 \gamma \beta_{l l}^{x}}}{2 \beta_{l l}^{x}}
$$

where $e_{l}=\beta_{l}^{x}+\sum_{j=1}^{s} \beta_{j l}^{x z} \ln \left(z_{j}\right)+\sum_{j \leq l} \beta_{j l}^{x} \ln \left(x_{j}\right)+\sum_{j \geq l} \beta_{l j}^{x} \ln \left(x_{j}\right)$ and we need that $e_{l}^{2}>4 \gamma \beta_{l l}^{x}$.

For individual output-oriented efficiencies for the $j^{\text {th }}$ output, $\tau_{O j}$, we have:

$$
\tau_{O j}=\tau_{R O}\left(\frac{\eta_{j}}{\tau_{R O}^{q} \eta_{j}+1-\tau_{R O}^{q}}\right)^{1 / q},
$$

where $\eta_{j}$ is the "share" of output $j$ described in (A6).

\section{Appendix B: Data}

Main sources of information for the data set include annual reports, press releases, other company reports and websites. This is supplemented with information and statistics from international, regional 
and national mining publications. The mine-level data for this analysis were derived from these sources and from a private mining consultancy group, the Raw Metals Group (RMG). The database used in this study has detailed information on a range of characteristics related to gold mining production: metal, grades, production information (metal and ore), resources, reserves, mining methods, and contact details for each company. All production data are at the mine level. Country characteristic data were derived from the World Bank Development Indicators (2001). Table 1 summarizes key characteristics of variables measured in the study: 


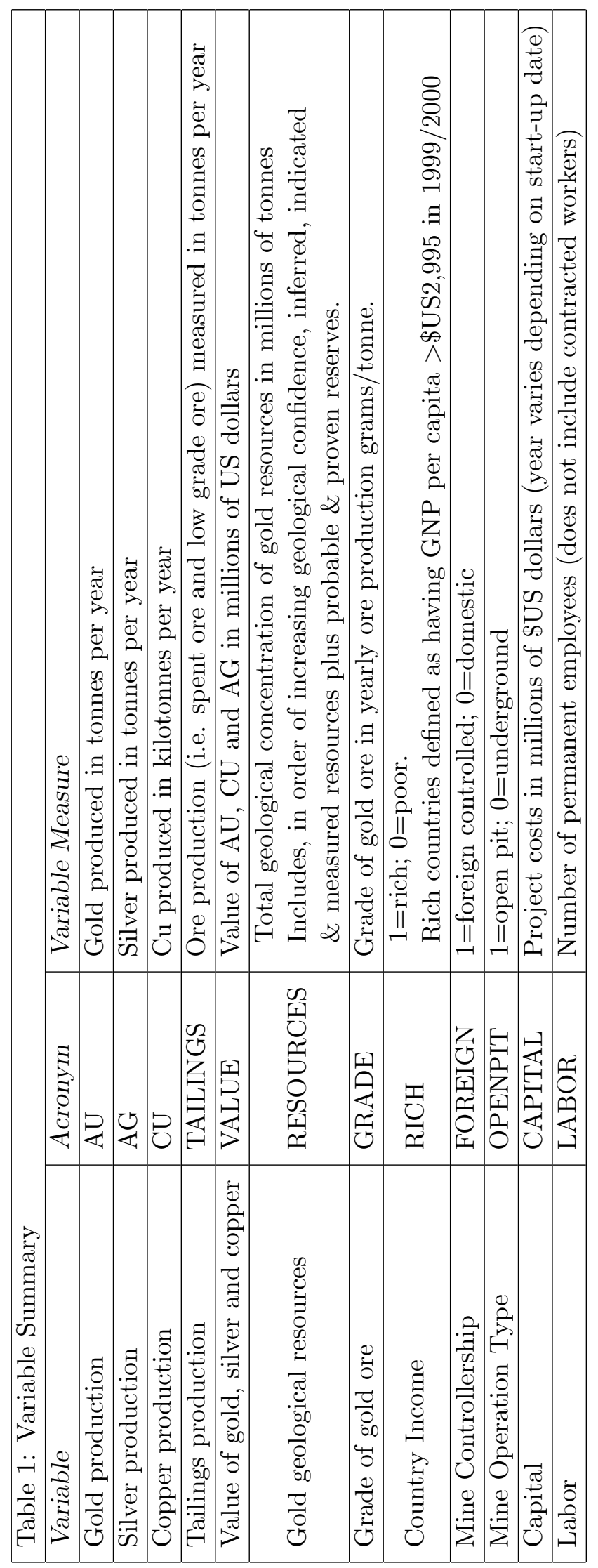




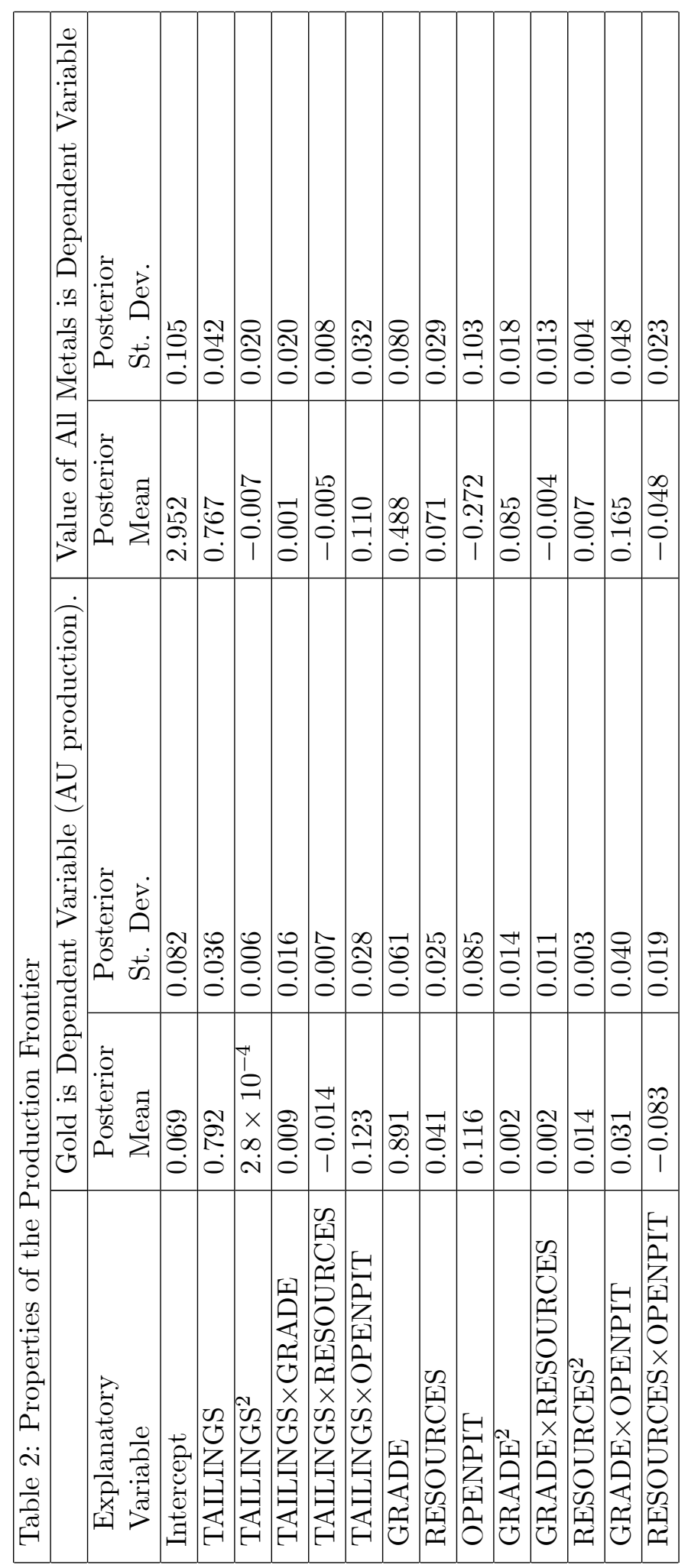




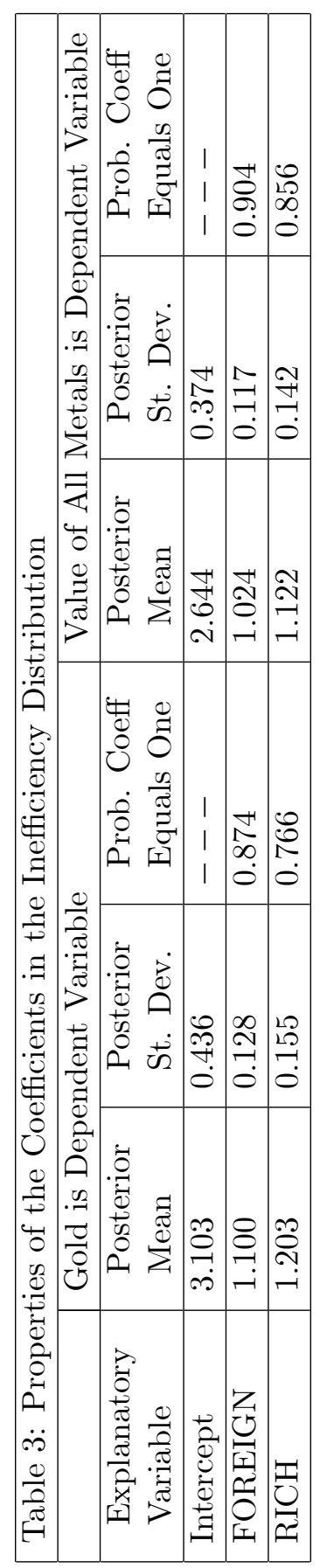




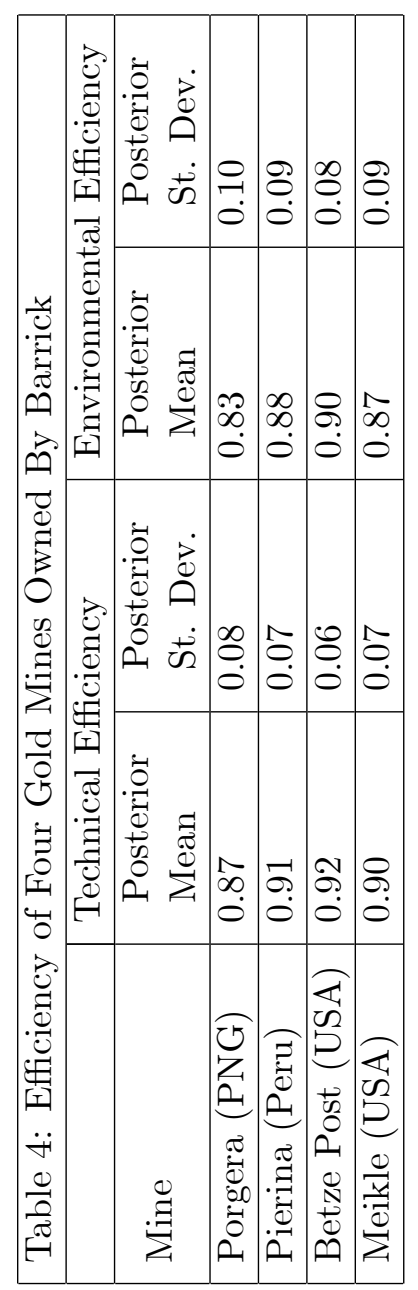




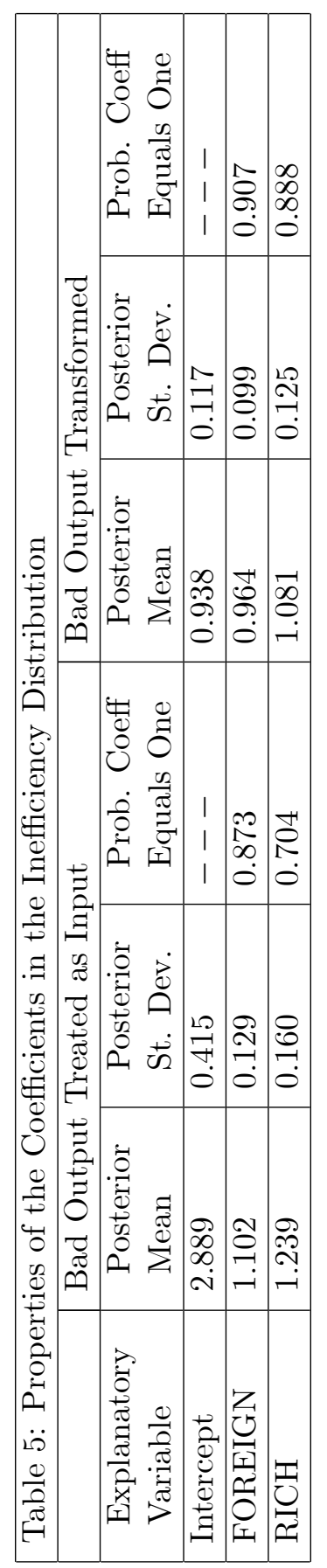




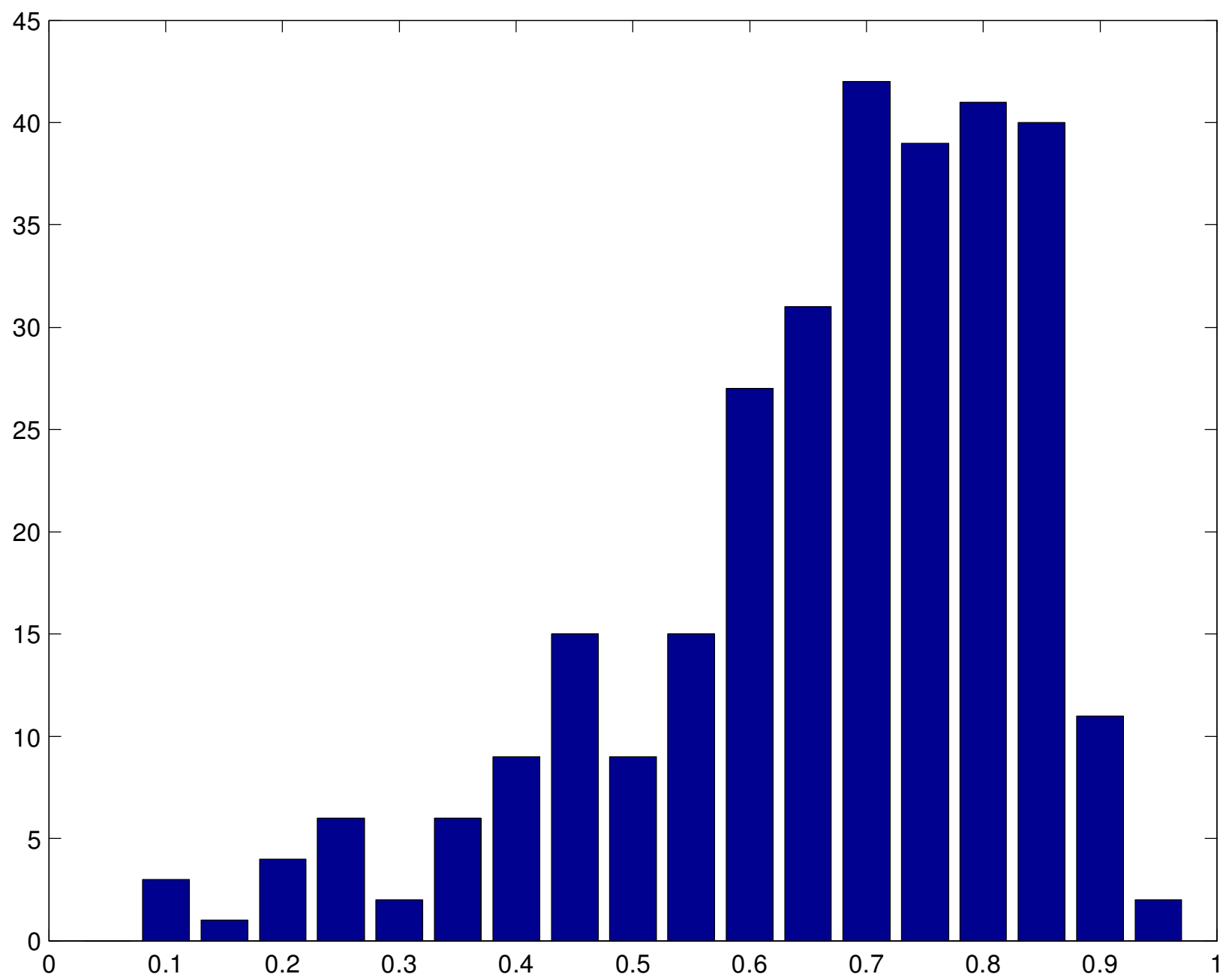

Figure 1: Environmental Efficiencies of Mines in Rich Countries 


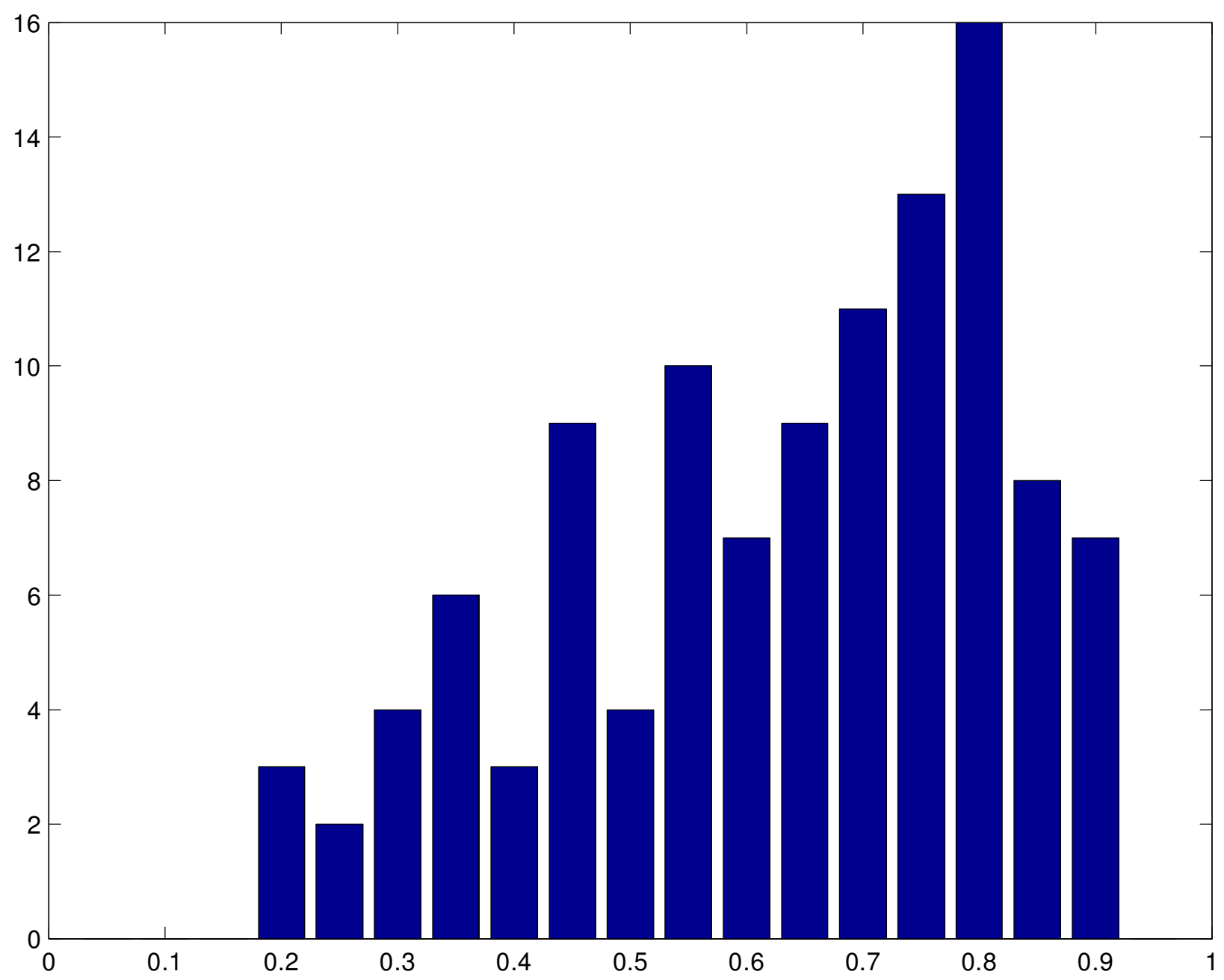

Figure 2: Environmental Efficiencies of Mines in Poor Countries 


\section{Notes}

${ }^{1}$ We have one bad output and hence such a measure can be used. We note in passing that, if several bad outputs are used, then environmental efficiency can be defined as a radial concept involving only the bads.

${ }^{2}$ This is particularly the case for cyanide use. In general, lower grades of ore require higher processing rates and therefore will use more cyanide, producing more tailings in the process. However, the relationship between cyanide use and tailings production will also depend on other factors, for example the geochemistry of the rock, the nature of the mining process (open pit vs. underground), the size of the mine, and so forth. Note, too, that cyanide is the only active form of the chemical, and as a result one can have very high WAD or total cyanide levels emitted but the chemical can nonetheless remain inactive in the environment and pose no damage to living organisms. Climate will play an important role in this outcome. Hence with cyanide and other non-geological measures of waste, it becomes more difficult to link waste to environmental impact, or the volume of waste produced to the mine's environmental performance. Simply looking at volume of cyanide use, for instance, would not provide as meaningful an environmental bad measure as simply using the volume of tailings produced.

${ }^{3}$ Formally, this is a specification for the mean of the distribution of the deviation from the frontier as defined in Appendix A.

${ }^{4}$ Results for technical efficiencies and for the foreign-owned/domestically owned categories show similar patterns and, hence, are not presented for the sake of brevity. 